\title{
CONCEPÇÃO DE TEXTO MULTIMODAL NA LEITURA DE INFOGRÁFICO DIGITAL POR MEIO DE PROTOCOLO VERBAL
}

Francis Arthuso Paiva ${ }^{1}$

\section{RESUMO}

O objetivo deste trabalho é apresentar evidências de que os elementos não verbais de um infográfico digital são sistematicamente processados pelo leitor assim como é feito com o texto verbal. A metodologia consistiu na submissão de infográfico digital a dois leitores adolescentes através da técnica de protocolo verbal para coleta de dados. A concepção de texto do ponto de vista unicamente discursivo, pragmático e semântico se demonstrou insuficiente para a análise dos dados. A concepção de texto multimodal, que inclui aspectos semióticos, foi mais útil para a análise dos dados. Os resultados evidenciam que modos visuais de veiculação de informação podem ser considerados elementos textuais não verbais, em decorrência da capacidade de os leitores testados de considerar as informações do modo visual na leitura do infográfico digital.

Palavras-chave: Texto. Multimodalidade. Infográfico.

\section{CONSIDERAÇÕES INICIAIS}

$\mathrm{Na}$ primeira seção, foram expostas concepções sócio-históricas de texto do ponto de vista discursivo, pragmático e semântico para demonstrar que nenhuma delas concebe os elementos não verbais como passíveis da textualidade. Compreende-se que os textos são organizados em gêneros como formas de organização de enunciados até certo ponto regulares, porque cada esfera de uso da língua organiza os enunciados de modo particular (BAKHTIN, 2003, p. 264-265). Postula-se, a partir dessa concepção de gênero textual, que os elementos não verbais também são parte constituinte da textualidade, ou seja, parte daquilo que faz da organização de elementos semióticos uma unidade a partir da qual se pode produzir sentido. No fim da seção, a concepção de texto multimodal de Kress e Van Leuween $(2001,2006)$ é apresentada como alternativa para análise de textos que são produzidos sem a predominância de um único modo semiótico.

Na seção seguinte, o infográfico digital Jogadores da Copa é apresentado como exemplo de texto multimodal. Ele foi usado no protocolo verbal realizado neste estudo. Na metodologia, expõem-se os procedimentos, sujeitos e materiais 
utilizados no protocolo verbal. Na sequência, os dados coletados são apresentados e analisados. Nas considerações finais, discutem-se as evidências ancoradas nas análises da leitura dos sujeitos no protocolo verbal.

\section{CONCEPÇÕES DE TEXTO}

Marcuschi disseminou no Brasil, na década de 1980, o que seria a Linguística de texto: "estudo das operações linguísticas e cognitivas reguladoras e controladoras da produção, construção, funcionamento e recepção de textos escritos ou orais" (MARCUSCHI, 1983, p. 26). O texto é conceituado nessa linha de estudo em uma concepção discursiva amparada nos estudos de Beaugrand e Dressler (1983), para quem a textualidade é uma complexa relação entre fatores de coerência, que são empregados na interpretabilidade e produção de um texto. Não se trata de dizer que o texto é apenas uma ocorrência maior do que uma sentença, mas que basta haver uma unidade linguística a partir da qual se pode produzir sentido para que ela seja considerada texto. O foco, nessa concepção, é no texto verbal falado ou escrito, sem referências a unidades não verbais a partir das quais se poderia produzir sentido.

Concomitantemente aos estudos da Linguística de texto, estudos sobre gêneros textuais despontaram, passando a ser o gênero textual uma entidade central nos estudos da linguagem, o que o atrelou ao conceito de texto, pois o texto se organiza em um gênero textual. Seguindo essa perspectiva, surge uma corrente de estudos dos gêneros textuais baseada na nova retórica, que considera o gênero textual como ação social. Para Bazerman (2006) e Miller (2009), o texto organizado em um gênero textual realiza atos de linguagem. $O$ texto deixa de ser apenas uma unidade linguística a partir da qual produzimos sentidos, para ser também uma unidade retórica que realiza ações entre sujeitos. São atos retóricos porque quem escolhe determinado gênero para organizar seu discurso o faz não apenas por determinações do contexto da esfera de atividade a que ele pertence, mas também o faz por determinada motivação em busca de um efeito pretendido. Para Miller (2009), a recorrência dessas ações retóricas é o que importa ao analisar o gênero textual, pois podemos tipificá-las. Para Bazerman (2006), é preciso observar as regularidades que geram recorrências, não apenas as regularidades da organização 
linguística, como também das ações retóricas. Essa corrente de estudos da linguagem ampliou a noção de gênero textual para além do princípio de interpretabilidade que um texto precisa ter para ser lido e produzido, na medida em que defende a ação retórica que o texto realiza nos leitores. Por exemplo, ao ler um anúncio de emprego, um desempregado desencadeia uma sequência de ações retóricas típicas como elaborar um currículo, enviá-lo, entrar em contato com a agência de emprego, realizar a entrevista de emprego. No entanto, essa concepção de gêneros textuais ainda não considerou no seu escopo as ações retóricas promovidas por textos não verbais.

Outra corrente de estudos da linguagem, a partir de um movimento mais crítico de linguistas encabeçados pelos trabalhos de Michael Halliday, defendeu que a relação entre significante e significado é motivada socialmente e não estabelecida de modo arbitrário e o sujeito passou a ser considerado um produtor de signos e não um mero codificador.

A partir dessa posição, Halliday e Matthiessen (2004) propuseram uma gramática sistêmico-funcional, o que significa que os termos são definidos pelos seus significados e não por sua posição na oração como nas gramáticas de sintaxe. Ela é sistêmica justamente porque acredita que as escolhas gramaticais são motivadas e não arbitrárias. Concomitantemente, ela é funcional porque promove subsídios para analisar qual é a implicação dessas escolhas no sistema gramatical. Para essa corrente, o texto não verbal ainda não seria considerado unidade de sentido. No entanto, o sistema de transitividade dessa gramática, bem como suas metafunções, ideacional, interpessoal e textual, motivaram Kress e Van Leeuwen (2006) a proporem a gramática do design visual, uma tentativa de sistematizar os procedimentos de produção e de leitura de imagens, assim como foi feito com o modo linguístico-verbal na gramática sistêmico funcional, a ponto de se propor um paralelo entre os dois modos, assim como as informações em modo linguístico articulam-se numa sintaxe, as informações no modo visual também possuem um sistema.

Nesse ponto de vista semiótico, para Kress e Van Leeuwen (2006), o verbal e o visual são considerados modos de veiculação do discurso. Eles carregam significados diferentes, porque são modos diferentes, cada qual apto para um tipo de informação, cada qual com limitações e habilidades distintas para apresentar 
informações. Um evento linguístico, por exemplo, pode narrar algo sem um protagonista, pois há recursos linguísticos para isso como pronomes, retirada do agente da passiva, entre outros. Já o visual precisa mostrar o evento acontecendo, com os atores, em tempo presente. Por outro lado, o linguístico tem dificuldades para representar eventos cíclicos. Para isso é necessário uso de várias orações. $\mathrm{O}$ visual possui recurso como setas em fluxogramas e esquemas para representar eventos cíclicos.

O discurso para Kress e Van Leeuwen (2001, p. 4) é "o conhecimento construído socialmente sobre (algum) aspecto da realidade" e está absolutamente relacionado ao seu modo de realização, além de afirmarem que o discurso se realiza em vários modos (KRESS e VAN LEEUWEN, 2001, p. 24). Ao afirmarem isso, os elementos apresentados na Gramática do design visual como cores, frames entre outros são considerados modos de realização do discurso. Esses autores também valorizam as sensações humanas, pois passam a considerar que material, que modo, que sentidos (visão, audição, etc) recebem melhor um discurso. O linguístico não é, portanto, o modo mais efetivo em todas as circunstâncias, já que alguns significados podem ser mais bem recebidos em um modo do que em outro. Eles chamam de prática comunicacional

a escolha do modo de realização do discurso que está mais apto a um propósito específico, a um público e à ocasião da produção do texto [...] que envolve seleção da forma material de realização entre um repertório cultural e do modo que o produtor julga ser mais efetivo em relação aos seus propósitos e o discurso a ser articulado. (KRESS e VAN LEEUWEN, 2001, p. 30-31).

Os sujeitos, ao utilizarem diferentes modos para veicularem seu discurso, produzem textos multimodais. Para Kress e Van Leeuwen (2001, p. 2) "a multimodalidade é a combinação de modos semióticos em uma produção ou evento semiótico". Portanto, para essa concepção de linguagem semiótica, o visual se constitui como texto, como unidade a partir da qual se pode produzir sentido. Para Lemke (2007), assim como os elementos do modo verbal são a nossa fonte para produzirmos sentido, os elementos do visual também se prestam a esse objetivo. Ao visualizarmos uma informação, isto é, utilizar o modo visual para representar uma informação que foi produzida em outro modo, nós nos baseamos em convenções, tipos, de acordo com uma sistemática (LEMKE, 2007). 
Portanto, a concepção de texto multimodal parece ser a mais adequada para considerar os elementos não verbais como passíveis da textualidade. Enfim, esta pesquisa tem como concepção a linguagem ser uma construção sócio-histórica, o infográfico digital é um exemplar contemporâneo significativo de uso da língua que se "efetua [...] em forma de enunciados (orais e escritos) concretos e únicos, proferidos pelos integrantes desse ou daquele campo da atividade humana" (BAKHTIN, 2003, p. 261-262). Temos que acrescentar ao conceito de gênero textual bakhtiniano o status de enunciado que é negligenciado às imagens, como afirmam Kress e Van Leeuwen (2001, 2006), Browett (2002) e Lemke (2007). Para esses autores, a imagem é um modo semiótico que faz parte da composição de enunciados produzida pelos sujeitos com suas escolhas, motivações e objetivos, tal como é feito com os enunciados do modo verbal. Dessa forma, os textos são, sim, fenômenos discursivos, pragmáticos e semânticos, mas não se pode prescindir, na concepção de texto, dos elementos não verbais que estão presentes em vários gêneros textuais como no infográfico digital.

\section{O INFOGRÁFICO DIGITAL}

O infográfico é um tipo de visualização de informação. Para Manovich (2011, p. 148), a visualização de informação é "um mapeamento entre dados discretos e uma representação visual [...] a partir de outras modalidades cognitivas (como a matemática) para uma modalidade de imagem". Ela pode ser impressa como feito até fins do século $X X$, antes do advento dos computadores, depois do qual foram produzidas versões digitais de visualizações de informação, sobretudo para a Web, o que contribuiu para que elas incorporassem recursos típicos desse meio como links, animações, banco de dados, vídeos entre outros.

Segundo Cairo (2008, p. 21), a informação verbal não é necessária para se produzir um infográfico, porém Paiva (2009, p. 136) observou que, nos infográficos presentes na revista impressa Superinteressante, a integração entre informações verbais e visuais parece ser uma recorrência que os tipifica. Essa tendência de integração de modos também é recorrente nos infográficos digitais, muito em decorrência da transposição de recursos do impresso para a tela digitalizada. A integração multimodal é o critério que diferencia o infográfico de outras visualizações 
de informação como mapas, fluxogramas, ilustrações, gráficos entre outras em que há predomínio de apenas um modo semiótico. Enfim, Valero Sancho (2008) define assim o infográfico digital.

\begin{abstract}
A infografia digital em seu sentido jornalístico, é uma apresentação informativa (não necessariamente no campo do jornalismo), que na maioria dos casos mostra infogramas em sequência sucessiva ou mista, elaborado para publicações audiovisuais digitais, cujas linguagens não são necessariamente linguísticas, feita por unidades icônicas elementares (fotos) ou complexos (mapas ou gráficos), dinâmicos ou não, completadas com tipografias signos gráficos e/ou auditivos, normalmente verbais e ligações interconectivas como legendas, citações e notas hipertextuais.
\end{abstract}

O infográfico utilizado neste estudo é o Jogadores da Copa do portal estadão.com. Trata-se de uma visualização de dados de uma pesquisa com o intuito de apontar a origem dos jogadores de futebol que participaram das Copas do Mundo de Futebol, torneio internacional desse esporte, em 2010, 2006, 2002, 1998 e 1994. Não origem natal, mas a origem do clube de futebol em que cada um dos jogadores participantes da Copa do Mundo atuava no momento em que não estava jogando futebol por sua seleção do país natal. O infográfico possui um gráfico para cada uma das Copas. Nele é possível visualizar duas informações principais. Primeira, saber de quantos países diferentes uma seleção recebeu jogadores. Segunda, quantos jogadores e para quais seleções um país enviou jogadores para a Copa do Mundo. Outra informação é a de que uma seleção pode inscrever 22 jogadores para participarem de uma Copa do Mundo, portanto, é possível saber de quais países vieram esses 22 jogadores de cada seleção. Mas, ao desejar saber quanto jogadores um país, através dos seus clubes, enviou à Copa do Mundo, esse número é variável. Isso porque um país pode ter em seus clubes jogadores de diversas nacionalidades, entretanto, em um evento como a Copa do Mundo, esses jogadores vão atuar em sua seleção natal. 
Figura 1 - Recurso de seleção barra inferior

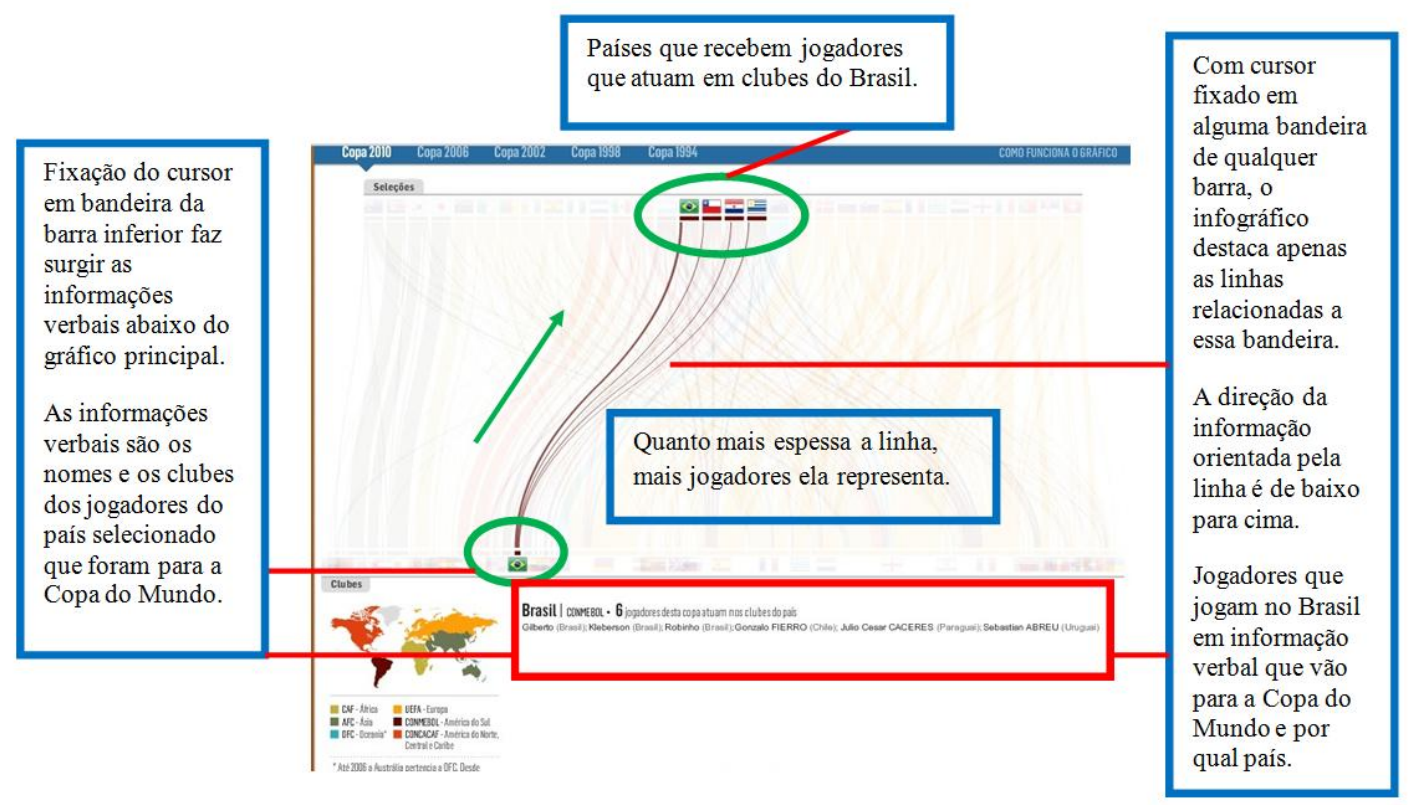

Fonte: estadao.com

Para Kress e Van Leeuwen (2006) o processo analítico relaciona participantes em termos de uma estrutura parte-todo. Os participantes são o portador (todo) e um número de atributos possessivos (as partes). Há subtipos de processos analíticos e o usado no infográfico Jogadores da Copa é o analítico espaço-temporal. As linhas do gráfico ligam portadores a seus atributos (KRESS e VAN LEEUWEN, 2006, p. 101-102). Ao fixar o cursor na barra de bandeiras inferior, a bandeira se torna portadora e as bandeiras de cima, ligadas pelas linhas, tornam-se atributos. Ao fixar em bandeira da barra superior, a relação se inverte 
Figura 2 - Recurso de seleção barra superior

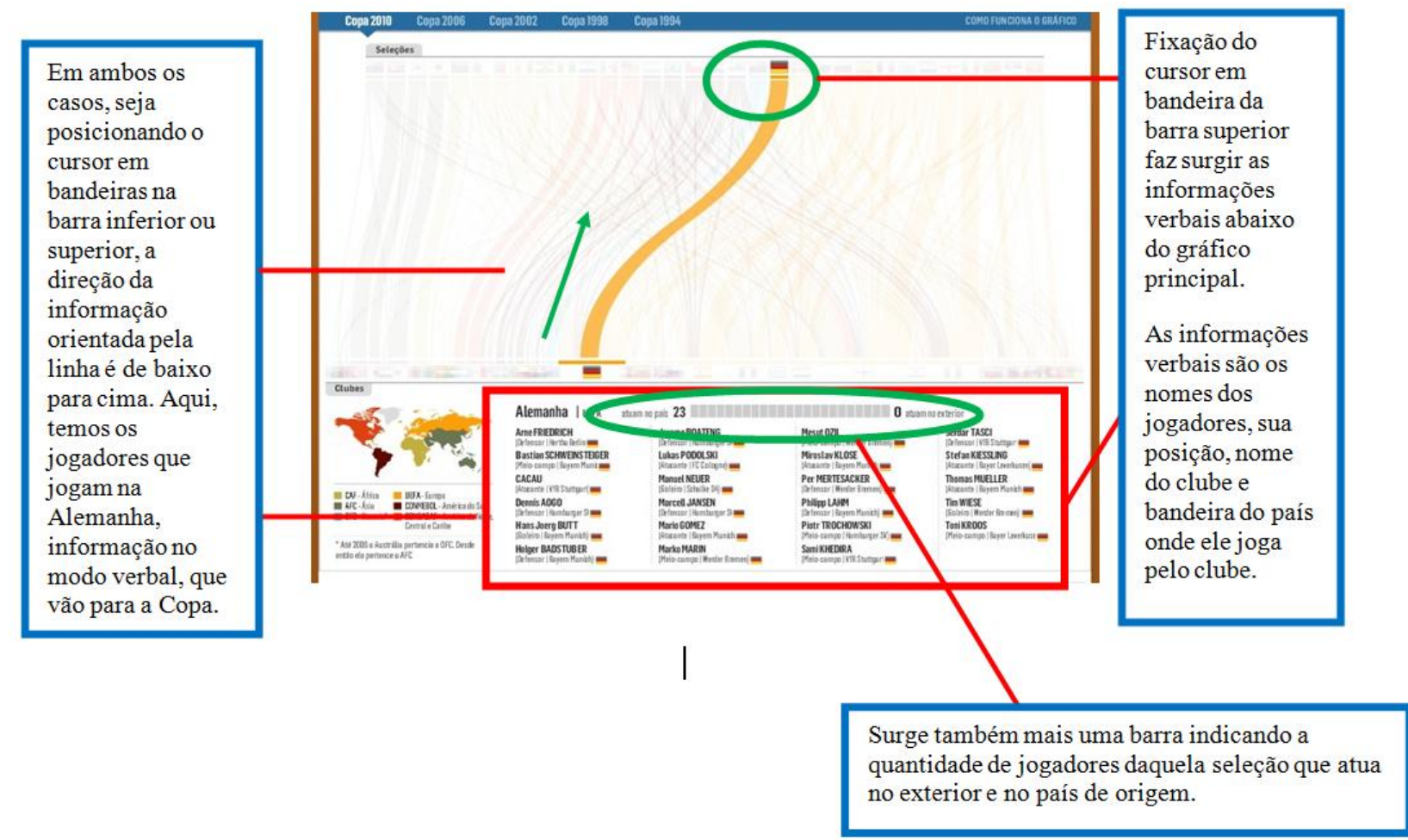

Fonte: estadao.com

Ao fixar o cursor sobre as bandeiras, surgem informações verbais. Verifica-se que essas informações no modo verbal ora são diferentes das informações do modo visual, ora são as mesmas informações. Foram selecionadas duas informações do infográfico Jogadores da Copa que são encontradas tanto em modo verbal quanto em modo visual para realização de um protocolo verbal com estudantes.

\section{METODOLOGIA}

A coleta dos dados foi feita por protocolos verbais de auto-observação, pois se mostra adequado para registrar o processamento da leitura, as escolhas, caminhos e motivações do informante durante uma tarefa de leitura. $O$ protocolo de autoobservação é a

descrição que o leitor faz de uma situação específica de leitura que acabou de fazer. Nesse tipo de protocolo verbal, apesar de os dados sobre a leitura já não estarem mais na memória de trabalho e o que temos então é uma 'percepção' do leitor sobre como se deu o seu próprio processo, essa percepção, por si só, pode ser importante para a pesquisa em questão ou para que possa ser feita uma triangulação com dados coletados através de outras ferramentas de pesquisa. (TOMITCH, 2007, p. 43-44). 
Trata-se de um método de coleta de dados com o mínimo de controle que garanta dados por parte do informante, uma vez que sem indução há o risco de que ele não verbalize tudo o que esteja fazendo e pensando como nos protocolos de pensar alto (think aloud), em que o informante descreve o que está fazendo e pensando durante a leitura. Os sujeitos são dois estudantes de quinze anos de idade, da $1^{\text {a }}$ série do Ensino Médio de escola técnica pública federal.

Foram feitas as seguintes perguntas sobre o infográfico Jogadores da Copa para esses dois estudantes.

1 - Qual seleção da Copa 2010 recebe mais jogadores que atuam em times da Espanha?

Resposta esperada. A resposta correta é a seleção da própria Espanha. O estudante precisaria fixar o cursor na bandeira da Espanha da barra inferior e avaliar que a linha que parte dela e a liga à bandeira da própria Espanha na barra superior, é a mais espessa, o que representa maior quantidade de jogadores, em relação às outras linhas que surgem concomitantemente. Ou ele poderia ler as informações verbais que surgem abaixo do gráfico principal.

2 - Os jogadores que atuam em clubes da Itália disputaram a Copa 2010 por quantos países diferentes?

Resposta esperada. A resposta correta é 20 países. O estudante precisaria encontrar a bandeira da Itália na barra inferior. Ao posicionar o cursor nela, apareceriam, na barra superior, as bandeiras das seleções ligadas por linhas. O estudante precisaria contar as bandeiras para dar a resposta. Ou ele poderia ler as informações verbais que surgem abaixo do gráfico principal.

Com a tela do monitor desligada, o seguinte comando foi dado ao estudante: "Leia o título introdutório e assim que terminar avise". A tela foi ligada e, após ele ler o texto introdutório, o pesquisador fez a primeira pergunta e, depois da resposta, fez-se a segunda pergunta.

O objetivo da tela desligada durante as explicações foi garantir que o estudante executasse as tarefas sem conhecer o infográfico para que suas respostas às tarefas fossem mais naturalísticas, para acompanharmos o seu processo de produção da leitura e não apenas os seus resultados. Caso fosse dado algum tempo 
para o estudante conhecer o infográfico antes das tarefas, o processo de produção da leitura seria perdido e ter-se-ia apenas o produto da leitura nas respostas.

O teste foi realizado em sala da mesma escola dos estudantes, utilizando o seguinte material: computador de mesa - PC desktop - com sistema operacional Windows XP, tela de LCD de 17 polegadas e microfone externo. Foi utilizado o navegador Google Chrome para acessar aos dois infográficos. O software Camtasia estava instalado nesse computador e funcionava perfeitamente, tanto a gravação de tela, quanto a gravação de áudio. Ambas ficaram com nitidez e nível de som perfeitos, contribuindo para a transcrição das respostas e descrição das ações na tela. O Software Camtasia Studio 8.0 grava a tela do computador durante seu uso e permite edições nos vídeos com a gravação de áudio e vídeo também. É a referência desse tipo de software.

\section{ANÁLISE DOS DADOS}

A seguir a transcrição das respostas às perguntas. Em negrito estão as falas do pesquisador, em itálico estão as descrições das ações na tela do estudante e em parênteses estão os comentários do pesquisador. No entremeio, estão as análises iniciais, que serão concluídas nas considerações finais.

\subsection{Estudante 1}

\section{1 - Qual seleção da Copa 2010 recebe mais jogadores que atuam em times da Espanha?}

Fixou na bandeira da Espanha na barra inferior. Depois fixou na bandeira da Espanha na barra superior. Novamente na Espanha, barra inferior. Levou o cursor para a parte inferior da página depois para o canto esquerdo. Passou o cursor sobre as bandeiras da barra superior da esquerda para a direita.

Não sei.

(repetição da pergunta)

Novamente passou o cursor sobre as bandeiras da barra superior até a metade. Foi com o cursor à barra inferior, retornou à superior e fixou nas bandeiras centrais em direção à direita. 
É, não sei. Achei que era pra olhar aqui em cima e a que tivesse maior faixa saindo da Espanha, mas... tudo mesma coisa.

Retornou com o cursor para a esquerda, passando o cursor pelas bandeiras até parar no centro.

\section{E quando você estava olhando embaixo? Você encontrou?...}

Esse aqui pra própria Espanha. Se fosse eu faria esse daqui Portugal. E a própria Espanha não seria resposta?

Fixou na bandeira da Espanha e em outras próximas. Depois fixou na bandeira de Portugal na barra superior, depois retornou para a bandeira da Espanha na barra inferior.

(repetição da pergunta)

Olha, a Espanha estaria dentro. Ou não.

Cursor fixado na bandeira da Espanha na barra inferior.

Qual é a informação que indica que ela recebe mais jogadores?

Por causa dessa faixa (linha do gráfico). Não estou achando outro lugar para achar essa informação não.

Passou o cursor sobre a linha que parte da bandeira da Espanha na barra inferior para a bandeira da Espanha na barra superior.

A faixa é mais larga, indica que são mais jogadores. Essa relação você já fez? Eu acho que é.

Novamente passou o cursor sobre a linha que parte da bandeira da Espanha na barra inferior para a bandeira da Espanha na barra superior.

\section{Qual seria a resposta?}

Espanha, provavelmente.

Fixou o cursor sobre as bandeiras da Espanha nas duas barras alternadamente, seguindo a linha que as liga.

\section{Como você chegou a essa resposta?}

Essa faixa laranja está mais acentuada pra cá.

Novamente fixou o cursor sobre as bandeiras da Espanha nas duas barras alternadamente, seguindo a linha que as liga.

\section{0 que indica que tem mais jogadores?}

A espessura dela.

Cursor fixado na bandeira da Espanha na barra inferior. 
ANÁLISE - O estudante 1 realizou adequadamente a tarefa 1 , respondendo Espanha, utilizando a barra inferior e indicando a espessura da linha como informação para avaliar sua resposta.

\section{2 - Os jogadores que atuam em clubes da Itália disputaram a Copa 2010 por quantos países diferentes?}

Deixa eu lembrar que eu não vou saber. Essa aqui é Itália.

(repetição da pergunta)

Fixou bandeira por bandeira na barra superior até fixar na bandeira da Itália. Depois fixou na bandeira da Itália na barra inferior. Clicou em ambas as bandeiras (sem link habilitado)

(repetição da pergunta)

Cursor fixado na bandeira da Itália na barra inferior.

(conta as bandeiras da barra superior que surgem ao se posicionar o mouse na bandeira da Itália na barra inferior)

20 países.

\section{Como você chegou a essa resposta?}

Coloquei (o cursor) na bandeirinha da Itália de clubes e olhei aqui em cima.

Cursor fixado na bandeira da Itália na barra inferior.

\section{Tinha outro jeito?}

Sei lá, foi o jeito que tinha na minha cabeça. Ler esses negócios aqui (texto em fonte pequena que surge abaixo do gráfico principal ao posicionar o mouse em alguma bandeira na barra inferior, contendo os nomes e o país de cada jogador que jogava na Itália e foi à Copa do Mundo, totalizando 80 jogadores).

Cursor fixado na bandeira da Itália na barra inferior.

\section{Qual é mais rápido, ler isso daí ou contar?}

Contar.

ANÁLISE - O estudante 1 realizou bem a tarefa 2. Fixou na bandeira da Itália na barra inferior de imediato e contou as bandeiras ligadas pelas linhas na barra superior, totalizando vinte bandeiras. Referiu-se às linhas do gráfico para avaliar a sua resposta. Para responder a essa pergunta, também é possível fixar o cursor em bandeira por bandeira na barra superior e em cada fixação conferir nas informações verbais se havia bandeira da Itália ao lado dos vinte e três jogadores da seleção 
fixada. É possível de se chegar à resposta fazendo esse procedimento, mas é mais trabalhoso. Com o cursor fixado na bandeira da Itália da barra inferior, também é possível contar quantas nacionalidades de jogadores diferentes existem atuando na Itália, mas isso tem que ser feito em meio a oitenta nomes enumerados num bloco único de texto verbal, em uma fonte de texto inapropriada para isso. Ou seja, foi dada pouca saliência a essa informação no modo verbal. A saliência é, nos textos multimodais, um importante recurso para organização das informações, pois ressalta os graus de importância entre os elementos que compõem o texto (KRESS e VAN LEEUWEN, 2006). Ao estudante 1 foi perguntado se haveria outra forma de se chegar à resposta da pergunta 2. Como ele estava com o cursor fixado na bandeira italiana na barra inferior, passou a ler os nomes dos países no bloco de texto. Perguntado de qual modo era mais fácil, ele respondeu que contar as bandeiras era mais fácil.

\subsection{Estudante 2}

1 - Qual seleção da Copa 2010 recebe mais jogadores que atuam em times da Espanha?

Fixou na bandeira da Espanha na barra inferior.

Pode incluir a própria Espanha?

Fixou na bandeira da Espanha na barra inferior.

Pode. É uma das seleções. Como você chegou a essa resposta?

Pela linha da Espanha, é mais grossa.

Fixou na bandeira da Espanha na barra inferior.

\section{Então o que a espessura da linha indica?}

Mais pessoas. Depois Portugal.

Fixou na bandeira da Espanha na barra inferior.

Depois vem Portugal?

Ahan! (confirmação)

Fixou na bandeira da Espanha na barra inferior.

Você está usando a parte debaixo.

Isso.

Depois fixou na bandeira da Espanha da barra de cima. 
ANÁLISE - O estudante 2 realizou adequadamente a tarefa 1, respondendo Espanha, não obstante, ter ficado em dúvida na hora de avaliar sua resposta, pois não tinha certeza se poderia ser a própria Espanha. Também iniciou procurando pela barra superior, alternando a fixação da bandeira espanhola também na barra inferior. Avaliou bem os dados surgidos com a fixação da bandeira na barra superior, pois ele não encontrou relação entre as linhas que pudesse ser resposta. Ele encontrou mais relação nas linhas surgidas com a fixação na barra inferior, utilizando-as para avaliar sua resposta.

\section{2 - Os jogadores que atuam em clubes da Itália disputaram a Copa 2010 por quantos países diferentes?}

Fixou na bandeira da Itália na barra inferior. (contou as bandeiras)

20.

\section{Como você chegou a essa resposta?}

Coloquei o mouse na bandeirinha da Itália, debaixo (barra inferior) e contei as bandeirinhas (barra superior).

Cursor fixado na bandeira da Itália da barra inferior. Clicou na bandeira (link não habilitado)

\section{Tem outra maneira de chegar a essa resposta?}

Eu acho que...

Cursor fixado na bandeira da Itália da barra inferior.

Você está lendo os países aqui? (Informação verbal abaixo do gráfico)

(confirmação)

Cursor fixado na bandeira da Itália da barra inferior.

\section{Mas é mais fácil contar as bandeiras ou ler?}

Mais fácil contar a s bandeiras.

Cursor fixado na bandeira da Itália da barra inferior.

ANÁLISE - O estudante 2 respondeu corretamente vinte países. Procurou bandeira por bandeira na barra superior até fixar na italiana, mas sem dificuldades. Depois fixou a mesma bandeira na barra inferior. Contou as bandeiras e respondeu. Também foi perguntado por qual modo seria mais fácil de chegar à resposta, pelo modo visual ou verbal, e, assim como o estudante 1 , também respondeu que seria mais fácil contar as bandeiras do que ler as informações verbais. 


\section{CONSIDERAÇÕES FINAIS}

Os dados fornecidos pelos estudantes no protocolo verbal apontam para duas conclusões a respeito da leitura que eles fizeram do infográfico. Primeiro que, no curso de processamento das informações, eles consideraram a informação de quantidade representada pela espessura das linhas do gráfico para responderem à primeira pergunta. Essas linhas, segundo Krees e Van Leeuwen (2006), são participantes do processo analítico topográfico dimensional e quantitativo, pois elas possuem uma escala de representação em que espaço significa quantidade. Essa relação foi interpretada pelos estudantes do protocolo verbal. Segundo que, na avaliação que fizeram das informações verbais e visuais na segunda pergunta, os estudantes consideraram as informações do modo visual mais fáceis de serem processadas, demonstrando empiricamente a prática comunicacional defendida por Kress e Van Leeuwen (2001), segundo a qual escolhemos o modo de realização do discurso pela sua aptidão em veicular informações mais propícia ora no modo verbal, ora no modo visual ou em outro modo semiótico.

Esses dados são evidências de que elementos do modo visual que compõem o texto multimodal precisam ser considerados nas análises textuais, seja na Linguística ou em outra área do conhecimento, cujo objeto de estudo seja o texto. Para esse propósito, os conceitos de análises multimodais propostas na Gramática do design visual se demonstraram uma opção adequada. Com essa proposta, acredita-se que será possível alçar outros modos semióticos à condição de elementos passíveis da textualidade em diferentes correntes de estudo do texto.

\section{NOTAS}

\footnotetext{
${ }^{1}$ Mestre em Estudos Linguísticos e Doutorando em Linguística Aplicada pela Faculdade de Letras da UFMG. Professor do setor de Letras do COLTEC-UFMG.
} 


\title{
CONCEIVING OF MULTIMODAL TEXT WHEN READING DIGITAL INFOGRAPHIC
} THROUGH VERBAL PROTOCOL

\begin{abstract}
The aim of this paper is to present evidences that the non-verbal elements of a digital infographic are systematically processed by the reader as it's done with the verbal text. The methodology consisted of the submission of digital infographic to two adolescent readers through verbal protocol technique for data collect. Conceiving of text from the only discursive, pragmatic and semantic viewpoint has shown insufficient for analysis of data. Conceiving of multimodal text that includes semiotic aspects was more useful for analysis of data. The results show that visual modes of propagation of information can be considered non-verbal textual elements, because of the ability of tested readers considering information in the visual mode in digital infographic reading.
\end{abstract}

Keywords: Text. Multimodality. Infographic.

\section{REFERÊNCIAS}

BAKHTIN, Mikhail. Estética da criação verbal. Trad. Paulo Bezerra. 3. ed. São Paulo: Martins Fontes, 2003 [1979].

BAZERMAN, Charles. Gêneros textuais, tipificação e interação. Trad. Judith Chambliss Hoffnagel. 2. ed. São Paulo: Cortez, 2006.

BEAUGRANDE, R.A.; DRESSLER, W. Introduction to text linguistics. Londres: Longman, 1983.

BROWETT, J. Critical literacy and visual texts: windows on culture. Impact, v. 11, n. 2, 2002. p. 24-29. Disponível em:

<http://www.fp.education.tas.gov.au/English/browett.htm>. Acesso em: 22 ago. 2009.

CAIRO, A. Infografia 2.0: visualización interactiva de información em prensa. Madrid: Alamut, 2008.

HALLIDAY, M. A. K.; MATTHIESSEN, C. M. I. M. An introduction to functional grammar. 3. ed. London: Arnold, 2004.

KRESS, Gunther; VAN LEEUWEN, Theo. Multimodal discourse: the modes and media of contemporary communication. London: Arnold, 2001. 2006 [1996].

Reading images: the grammar of visual design. 2. ed. London: Routledge, 
LEMKE, Jay L. Visual and verbal resources for evaluative meaning in political cartoons. 2007. Disponível em: <www-

personal.umich.edu/ jaylemke/papers/polcart.htm>. Acesso em: jun. 2012.

LEMOS, C; LIMA, D. Onde atuam os 736 jogadores da Copa 2010. Estadao.com, São Paulo, jun. 2010. Esportes. Disponível em:

<http://www.estadao.com.br/especiais/onde-atuam-os-736-jogadores-da-copa-

2010,107780.htm>. Acesso em 20 fev. 2012.

MANOVICH, Lev. O que é visualização. Estudos em jornalismo e mídia, Florianópolis, v. 8 n. 1, p. 146-172, 2011. Disponível em:

<http://www.periodicos.ufsc.br/index.php/jornalismo/issue/view/1523/showToc>.

Acesso em: 30 jan. 2012.

MARCUSCHI, Luiz Antônio. Linguística de texto: o que é e como se faz? Recife: allprint, 1983.

MILLER, Carolyn. R. Gênero como ação social. In: . Estudos sobre gênero textual, agência e tecnologia. Recife: Editora [da] UFPE. p. 21-44.

PAIVA, F. A. A leitura de infográficos da revista Superinteressante: procedimentos de leitura e compreensão. Dissertação (Faculdade de Letras - Mestrado em Estudos Linguísticos) - Universidade Federal de Minas Gerais, Belo Horizonte, UFMG, 2009.

PELTZER, Gonzalo. Jornalismo iconográfico. Lisboa: Planeta, 1991.

TOMITCH, Lêda Maria Braga. Desvelando o processo de compreensão leitora: protocolos verbais na pesquisa em leitura. Signo, Santa Cruz do Sul, v. 32 n. 53, p. 42-53, dez. 2007. Disponível em:

<http://online.unisc.br/seer/index.php/signo/article/viewFile/244/197> Acesso em: 30 jun. 2008.

VALERO SANCHO, J. L. La infografía digital en el ciberperiodismo. Revista Latina de Comunicación Social, La Laguna (Tenerife), n. 63, p. 492-504, 2008. Disponível em <http://www.ull.es/publicaciones/latina/ml>. Acesso em 25 nov. 2011. 